\title{
Odor identification in young and elderly African-Americans and Caucasians
}

Olfactory function is affected by
age and gender. However, there are
few data on smell function in various
racial/cultural groups, in particular,
in different-aged African-Americans.
Therefore, this study sought to deter-
mine if there is a relationship among
age, gender, and race for smell iden-
tification. Sixty healthy African-
Americans and 60 Caucasians
between the ages of $20-40$ and $60-$
80 years were administered the
University of Pennsylvania Smell
Identification Test (UPSIT). Older
persons, regardless of race, had
lower UPSIT scores, were more Iikely
to be microsmic and anosmic, and
had increased chemosensory com-
plaints. Smell performance among
females was better compared with
males. Overall, African-Americans
had lower UPSIT scores and age- and
gender-adjusted percentile rank
scores compared with Caucasians,
but these differences were signifi-
cant only among younger subjects.
In addition, both young and old
African-Americans had no smell com-
plaints. The results from this study
suggest that age, gender, and race
have an influence on smell identifica-
tion.

0 lfaction warns individuals about food spoilage, dangerous fumes, and fires, and determines the flavor and palatability of foods and beverages. ${ }^{1}$

Unfortunately, chronic disorders of smell and taste are frequently neglected, although chemosensory disorders can be diagnostic signs of more serious diseases and anomalies. ${ }^{1}$

There are many factors that may cause olfactory dysfunction. The most common are medications and systemic diseases such as Alzheimer's and Parkinson's diseases, diabetes mellitus, hypothyroidism, and hypertension. ${ }^{2}$ Olfactory disturbances often result from head trauma, upper respiratory infection, and nasal and/or paranasal sinus disease. ${ }^{1}$ Furthermore, indoor and outdoor environmental pollutants can contribute to olfactory dysfunction. ${ }^{3}$

Chemosensory dysfunction has a profound affect on the health and function of an individual. Patients with chemosensory dysfunction tend to present with low body weight, nutritional deficiencies, and depression. ${ }^{1}$ There is evidence to suggest that symptoms of psychological depression are greatest in patients with smell and taste dysfunction. ${ }^{1}$ Chemosensory dysfunction affects the quality of a person's life.

Therefore, these individuals should be identified in order to prevent further morbidity and mortality. ${ }^{1,2}$

Investigations of olfactory function reveal age-related declines and gender differences, with females possessing superior smell capacity compared with that of males. ${ }^{4,5}$ In addi- tion, there are cultural, geographic, and individual variations in olfactory function. ${ }^{3}$ Wysocki et al. ${ }^{3}$ suggested that cultural or geographic differences in olfactory preference may, in part, be influenced by an individual's social status, or by food preparation and taste preferences. In addition, genetics and physiology as well as hygiene habits influence olfactory function. However, little research has been dedicated to examining the role of cultural, geographic, or racial factors in olfaction.

In the United States, the majority of olfactory studies have focused primarily on Caucasian populations. There are few data on odor identification in various racial/cultural groups, in particular, in differentaged African-Americans. Therefore, the purpose of the present study was to determine if there is a relationship among age, gender, and race on smell identification.

\section{Materials and Methods}

\section{Population}

The study population consisted of 60 African-Americans and 60

Caucasians. Thirty-eight young (age 20-40 years) and 22 old (age 60-80 years) subjects were examined within each racial group. Young AfricanAmericans (age $28.7 \pm 5.6$ years, mean \pm SD) and Caucasians (30.6 \pm $5.8 \mathrm{yrs}$ ) were similar in age (Student's $t$ test, $\mathrm{p}>0.05)$, and old AfricanAmericans $(69.7 \pm 4.8 \mathrm{yrs})$ and Caucasians (72.3 \pm 6.9 yrs) were similar in age (Student's $t$ test, $\mathrm{p}>0.05$ ). Caucasians were volunteer participants in the oral physiology compo- 
nent $^{6}$ of the Baltimore Longitudinal Study of Aging (BLSA) conducted by the National Institute on Aging.?

African-American subjects were volunteer participants in the Howard University/National Institute of Dental Research (HU/NIDR) oral physiology study of aging, 8,9 which was designed to parallel the oral physiology component of the BLSA.

Each Caucasian subject was ageand gender-matched to an AfricanAmerican subject. All subjects were community-dwelling and of middle socio-economic class. Young subjects were healthy, not being treated for any medical problems, and were not taking any prescription medications. In each older group of AfricanAmericans $(\mathrm{n}=22)$ and Caucasians ( $\mathrm{n}$ $=22$ ), there were nine healthy unmedicated subjects, and 13 subjects with no existing medical problems except well-controlled hypertension, according to criteria established by Weber et al. ${ }^{10}$ The subjects being treated for hypertension were taking one of the following medications: diuretic, calcium channel blocker, nonselective beta-adrenergic blocking agent, and angiotensin converting enzyme inhibitor. A resting blood pressure was taken on every subject, and values were similar in AfricanAmericans and Caucasians. All diastolic blood pressures were under 95 $\mathrm{mm} \mathrm{Hg}$ and all systolic blood pressures under $156 \mathrm{~mm} \mathrm{Hg}$.

In the present study, a smoking history was assessed for each subject. Subjects were categorized as nonsmokers, former smokers, and current smokers. The influence of smoking status on smell identification was evaluated.

\section{Odor identification}

Odor identification was assessed with the University of Pennsylvania Smell Identification Test [UPSIT], as described previously. $4,11,12$ Briefly, the UPSIT is a standardized 40-stimulus micro-encapsulated "scratch-andsniff" forced-choice odor identification test. In addition, a two-item chemosensory questionnaire was administered to all subjects to identi-

Table. Prevalence (\%) of responses ${ }^{1}$ to chemosensory questions by race and age group.

\begin{tabular}{|c|c|c|c|c|}
\hline Race/Age Group & $\begin{array}{c}\text { Changesmell }{ }^{2} \\
\text { No Change }\end{array}$ & Worse & $\begin{array}{l}\text { Changetaste }^{3} \\
\text { No Change }\end{array}$ & Worse \\
\hline $\begin{array}{l}\text { Young } \\
\text { African-Americans } \\
(\mathrm{n}=38)\end{array}$ & $38 / 38(100 \%)$ & $0 / 38(0 \%)$ & $36 / 38(95 \%)$ & $1 / 38(3 \%)^{4}$ \\
\hline $\begin{array}{l}\text { Young } \\
\text { Caucasians } \\
(n=38)\end{array}$ & $36 / 38(95 \%)$ & $2 / 38(5 \%)$ & $37 / 38(97 \%)$ & $1 / 38(3 \%)$ \\
\hline $\begin{array}{l}\text { Old } \\
\text { African-Americans } \\
(\mathrm{n}=22)\end{array}$ & $22 / 22(100 \%)$ & $0 / 22(0 \%)$ & $21 / 22(95 \%)$ & $0 / 22(0 \%)^{4}$ \\
\hline $\begin{array}{l}\text { Old } \\
\text { Caucasians } \\
(n=22)\end{array}$ & $17 / 22(77 \%)$ & $5 / 22(23 \%)$ & $18 / 22(82 \%)$ & $4 / 22(18 \%)$ \\
\hline
\end{tabular}

${ }^{1}$ Responses "improved" or "no change" were analyzed as "no change".

${ }^{2}$ Have you experienced any changes in your sense of smell?

${ }^{3}$ Have you experienced any changes in your sense of taste?

"One subject responded "other".

fy subjective complaints of smell and taste changes. ${ }^{12}$ The questions were: (a) "Have you experienced any change in your sense of smell?" (changesmell), and (b) "Have you experienced any change in your sense of taste?" (changetaste).

\section{Analysis}

UPSIT scores were converted into three olfactory functional categories: normosmic, microsmic, and anosmic. ${ }^{13}$ UPSIT scores were also converted into age- and genderadjusted percentile rank scores ${ }^{13}$ based upon normative data. UPSIT scores and percentile rank scores were initially analyzed according to age, gender, and racial group by MANOVA tests. UPSIT results indicated that age and race were significant, but that the interaction between these two factors was not. Percentile rank score results indicated that only race was significant. Thereafter, intragroup differences were analyzed by Student's $t$ tests and Mann-Whitney tests. Differences between the hyper- tensive and non-hypertensive groups were analyzed by Student's $t$ tests and Mann-Whitney tests. The influences of age, gender, race, and hypertension status on olfactory functional categories were analyzed by Chisquare tests and Fisher's exact tests. Differences in the frequency of responses to the chemosensory questionnaire according to age, gender, racial group, and hypertension status were evaluated by Chi-square tests and Fisher's exact test. The responses of "improved" or "no change" were combined and analyzed as "no change". In addition, the sensitivity and specificity of responses to the two chemosensory questions in relation to unimpaired smell (normosmic) or impaired smell (microsmic and anosmic) ${ }^{12}$ were evaluated.

The influence of smoking status on smell identification in AfricanAmerican and Caucasian groups was analyzed by Chi-square tests and Fisher's exact test. Smoking status was similar between both groups. Forty-one African-Americans and 33 Caucasians were nonsmokers; 12 
African-Americans (mean pack years $=15$ ) and 22 Caucasians (mean pack years = 14) were current smokers; seven African-Americans (mean pack years $=15$ ) and five Caucasians (mean pack years $=8$ ) were current smokers. One pack year was defined as smoking one pack of cigarettes daily for one year, or one-half pack of cigarettes daily for 2 years, etc. In the present study, statistical tests revealed that smoking status had no significant influence on smell identification.

Data were analyzed by means of the RS1 software package (BBN Software Products, Cambridge, MA). A criterion of $p<0.05$ was accepted for significance in all statistical tests.

\section{Results}

\section{Age/gender}

Age had a significant influence on UPSIT scores (Fig 1). Overall, young subjects had significantly higher UPSIT scores compared with old subjects (Student's $t$ test, $\mathrm{p}=0.0001$ ). No gender differences were observed in either the young- or old-aged groups; however, females, in general, had higher UPSIT scores compared with males, but these differences were not significant. Young males had significantly higher UPSIT scores than old males (Student's $t$ test, $\mathrm{p}=0.003$ ), but these age-related differences were not significant among the females.

Using normative data for comparisons with previous studies, ${ }^{13}$ we converted UPSIT scores to percentile rank scores (Fig 2). There was no significant effect of age or gender on percentile rank scores (MANOVA, $\mathrm{p}$ $>0.05$ ).

Using functional categories (normosmic, microsmic, anosmic), we compared unimpaired (normosmic) with impaired (microsmic and anosmic) individuals. Overall, older people were more likely to be impaired $(43 \%)$ compared with younger people ( $3 \%$; chi-square, $p=0.001)$; however, no significant gender differences were observed. Younger males (97\%) were more likely to be normosmic compared with older males (57\%; chi-

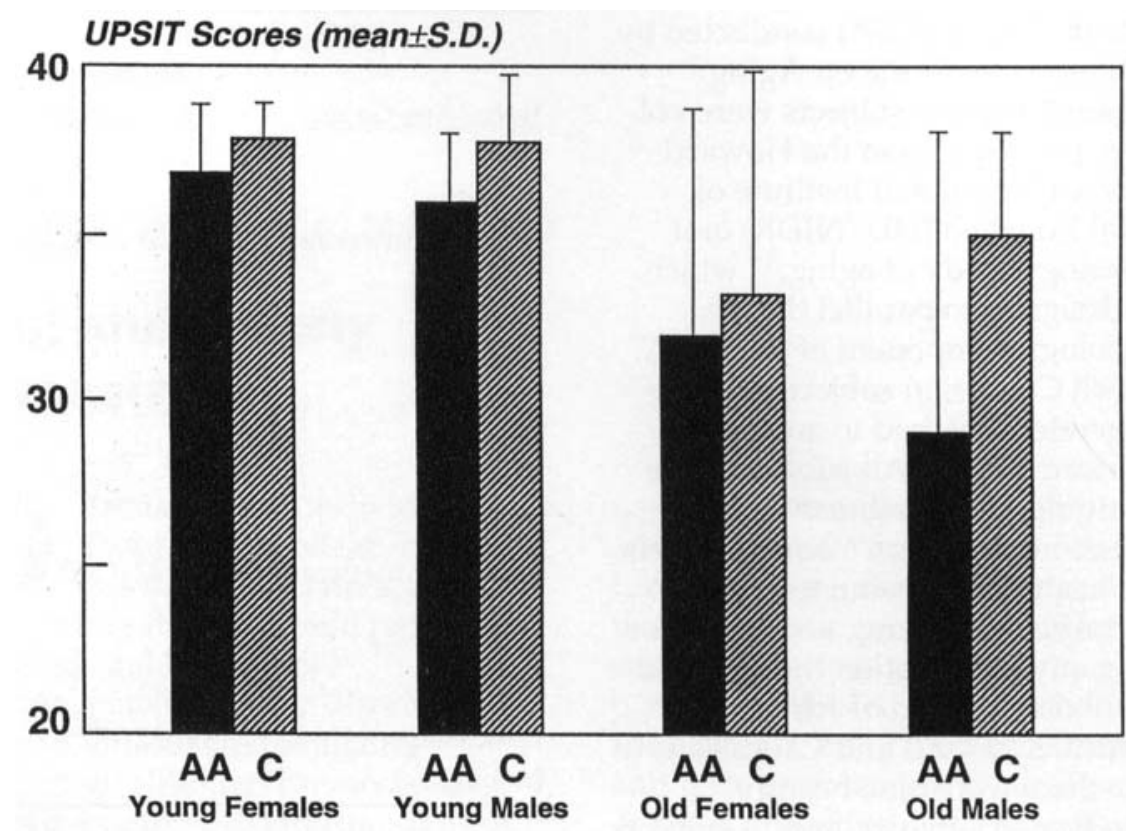

Fig 1. UPSIT scores for African-American (AA) and Caucasian (C) males and females in young (age 20-40 years) and old (age 60-80 years) groups.

square, $\mathrm{p}=0.001)$. Similarly, younger females $(97 \%)$ were more likely to be normosmic compared with older females (57\%; chi-square, $p=0.001)$.

\section{Race}

Overall, Caucasians had higher UPSIT scores compared with AfricanAmericans (Student's $t$ test, $\mathrm{p}=0.002$ ) (Fig 1). This difference was observed in the young population (Student's $t$ test, $p=0.02$ ), but not in the old population. Old age was associated with lower UPSIT scores in both Caucasian and African-American subjects. There were no differences between males and females within each racial group; however, Caucasian males and females had significantly higher UPSIT scores compared with African-American males (Student's $t$ test, $p=0.02$ ) and females (Student's $t$ test, $\mathrm{p}=0.03$ ). Young African-American and Caucasian males had significantly higher UPSIT scores than old African-American (Student's $t$ test, $\mathrm{p}$ $=0.002$ ) and Caucasian (Student's $t$ test, $p=0.004$ ) males. No significant differences were noted between young and old females within either racial group.

Percentile rank scores for all study participants are illustrated in Fig 2. In general, there were no gender or age differences, since values were adjusted according to normative data. ${ }^{13}$ Caucasians had higher percentile rank scores than African-Americans (Student's $t$ test, $\mathrm{p}=0.001$ ); however, these differences were significant only for young males (Student's $t$ test, $\mathrm{p}=0.009$ ) and females (Student's $t$ test, $\mathrm{p}=0.03)$. There were no differences in percentile rank scores between males and females within each racial group; however, Caucasian males had higher scores compared with African-American males (Student's $t$ test, $\mathrm{p}=0.002$ ), and Caucasian females had higher scores compared with African-American females (Student's $t$ test, $p=0.008$ ).

Regarding functional categories, there was a greater proportion of normosmic Caucasians (87\%) compared with normosmic African-Americans (75\%; chi-square, $p=0.007$ ). These racial differences were consistent in both young and old groups, although they were not statistically significant. Age-related changes in the proportion of impaired subjects were great- 


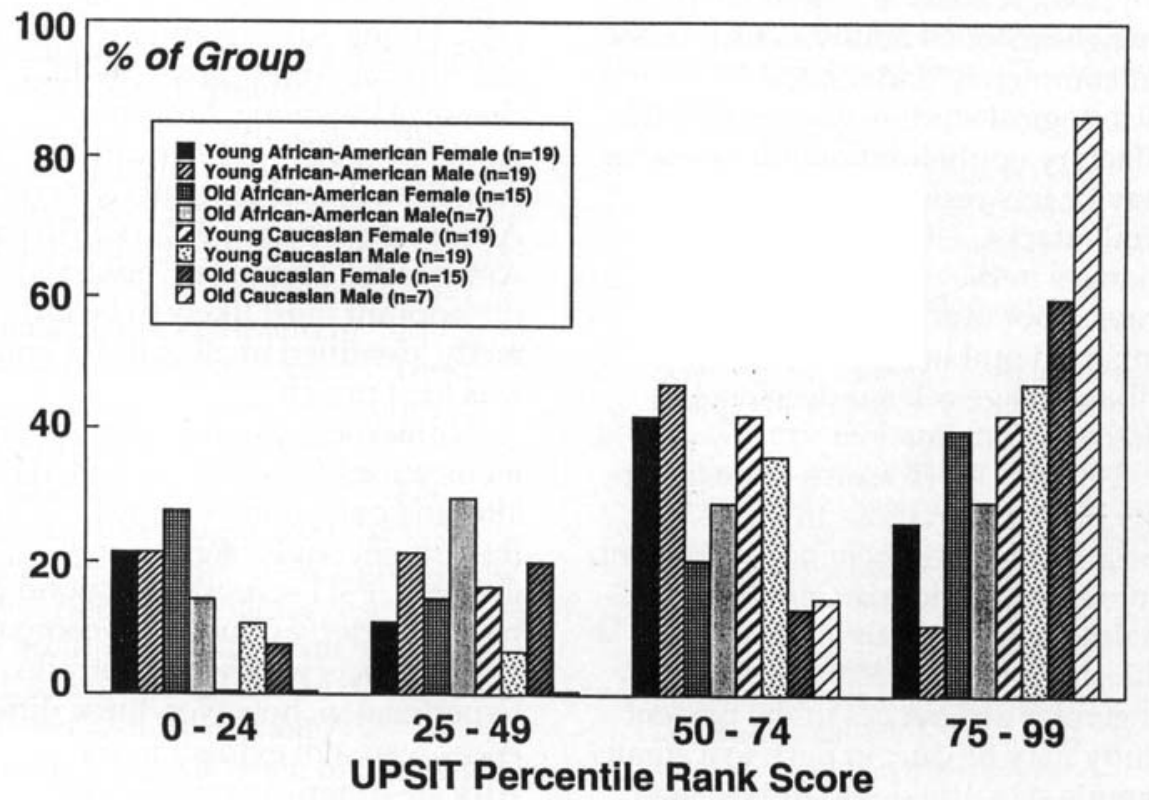

Fig 2. UPSIT percentile rank based on scores in young (age 20-40 years) and old (age 60-80 years) African-American and Caucasian males and females.

est in the African-American group, where elderly subjects $(41 \%$ microsmic, $18 \%$ anosmic) had a greater prevalence of impairment compared with young subjects $(5 \%$ microsmic, $0 \%$ anosmic; chi-square, $\mathrm{p}=0.001$ ). Within the Caucasian group, elderly subjects ( $32 \%$ microsmic, $4 \%$ anosmic) also demonstrated greater functional impairment compared with young subjects ( $0 \%$ microsmic, $0 \%$ anosmic; chi-square, $p=0.001$ ). Overall, Caucasian males were more likely to be normosmic compared with African-American males (chisquare, $p=0.04$ ), but these differences were not observed for females. Concerning the interaction of age and gender, young African-American and Caucasian females had a greater prevalence of normosmic subjects compared with old African-American (chi-square, $\mathrm{p}=0.04$ ) and old Caucasian (chi-square, $p=0.004$ ) females. Young African-American males were more likely to be normosmic compared with old AfricanAmerican males (chi-square, $\mathrm{p}=$ 0.01 ), but these differences were not observed among the Caucasian males.

\section{Responses to chemosensory questions}

Older individuals $(5 / 44=11 \%)$ were more likely to complain of a change in their sense of smell, but not a change in taste, compared with young subjects $(2 / 76=3 \%$; chisquare, $p=0.05$ ) (Table). Males and females responded similarly to these two questions, and there were no age-related differences in responses.

Caucasians $(7 / 60=12 \%)$ were more likely to complain of a change in smell compared with AfricanAmericans $(0 / 60=0 \%$; chi-square, $p$ $=0.006$ ). These significant racial differences were observed in the oldaged group (chi-square, $p=0.02$ ), but not in the young group. In addition, significant differences were observed between young and old Caucasians (chi-square, $p=0.04$ ). None of the African-Americans reported that their sense of smell had gotten worse. Overall, no differences in response to the changetaste question were observed between African-Americans and Caucasians. However, significant differences were evident between young and old Caucasians (chisquare, $p=0.04$ ), but not among African-Americans.

\section{Sensitivity/specificity of chemosensory questions}

Changesmell: The sensitivity to the changesmell question was $0 \%(0 / 2)$ in the young group and $9.5 \%(2 / 21)$ in the old group. The specificity for this question was $89 \%(66 / 74)$ in the young group and $88 \%(22 / 25)$ in the old age group. Females $(14 \%, 2 / 14)$ had a greater sensitivity than males $(0 \%)$, yet the specificity was similar between females $(94 \%, 51 / 54)$ and males $(95 \%, 43 / 45)$. The sensitivity to this question was lower among African-Americans $(0 \%, 0 / 15)$ compared with Caucasians $(25 \%, 2 / 8)$, yet the specificity was similar in African-Americans $(100 \%, 47 / 47)$ and Caucasians $(90 \%, 47 / 52)$.

Changetaste: The sensitivity of the changetaste question was also low and demonstrated age- and racerelated differences, but no gender differences. Younger individuals $(50 \%$, $1 / 2$ ) had a greater sensitivity compared with older persons $(9 \%, 2 / 21)$. Caucasians $(25 \%, 2 / 8)$ had a greater sensitivity than African-Americans $(0 \%, 0 / 15)$. Specificity for this question overall was good (males $97 \%$, 44/45; females $92 \%, 50 / 55$; young African-Americans 94\%, 34/36; young Caucasians 97\%, 37/38; old African-Americans 100\%, 11/11; old Caucasians $86 \%, 12 / 14$ ) and demonstrated no significant age, gender, or racial differences.

\section{Hypertension/medication effect}

No gender differences for UPSIT scores were observed between healthy subjects and individuals being treated for hypertension. In the older age groups, UPSIT scores were similar in males and females for both healthy subjects and individuals being treated for hypertension, and thereafter all analyses combined males and females. UPSIT scores were significantly higher for healthy Caucasians compared with 
Caucasians being treated for hypertension (Student's $t$ test, $\mathrm{p}=0.005$ ), but no differences were detected in the African-American group.

Percentile rank scores were similar between healthy and hypertensive groups regardless of race. For older Caucasians, the prevalence of normosmia was greater among healthy subjects $(8 / 9,89 \%)$ compared with hypertensive subjects $(6 / 13,46 \%)$, but a similar difference was not detected between healthy $(4 / 9,44 \%)$ and hypertensive $(7 / 13,54 \%)$ older African-Americans.

\section{Discussion}

The results from this study suggest that age and, to a lesser extent, race have a significant influence on smell identification in a population of generally healthy individuals. Older persons, regardless of race, had lower UPSIT scores, were more likely to be microsmic and anosmic, and had increased chemosensory complaints. Overall, smell performance among females was higher compared with males; however, these differences were not statistically significant. Racial comparisons revealed that Caucasians had higher UPSIT and adjusted percentile rank scores, were less likely to be smell-impaired, and had increased complaints of smell problems. In general, racial differences were most evident in the young groups, with no differences observed in the older groups with the exception of the chemosensory questions. Young and old African-Americans in this study had no complaints of smell problems. Finally, in a small group of older Caucasians with well-controlled hypertension and taking one antihypertensive drug, smell identification was further impaired.

These age-related findings are consistent with previous studies demonstrating that smell identification declines with increased age. ${ }^{4,12,14,15,30,31}$ Despite the small sample size in this study, age-related olfactory function deficits were detected in healthy AfricanAmericans and Caucasians. These declines support an anatomic and physiologic basis for age-related changes in smell ability, which is not yet completely understood. ${ }^{15}$

Histological studies suggest that the olfactory epithelium of older persons may be less resistant to damaging viral attacks. ${ }^{13,16-20}$ In addition to changes in the central neural pathways, poor oral hygiene and impaired oral health may also contribute to age-related decreases in olfactory function. ${ }^{12,22}$

Female UPSIT scores were generally higher than those in males, but these differences were not significant. Interestingly, elderly Caucasian males scored slightly higher than elderly Caucasian females. The lack of gender differences in the present study may be due, in part, to a small sample size. Previous studies have demonstrated superior olfactory function in females, ${ }^{4,5,23}$ including healthy populations. ${ }^{12}$ When the UPSIT was administered to four different ethnic groups in one study, women consistently outperformed men to the same relative degree. ${ }^{5}$ It is not yet known why olfaction is influenced by gender, although several hypotheses have been stated. Deems et al. ${ }^{1}$ suggested that estrogen has a prophylactic effect on the integrity of the olfactory epithelium, protecting it from viral or toxic insults.

Racial differences existed in smell identification in the present study, but only in the young group. Doty et $a l .5$ used a considerably larger sample size, yet also found racial differences. However, Doty's cohorts were not age-matched. Doty et al. ${ }^{5}$ collected UPSIT scores from four racial groups: American Koreans ( $92 \%$ correct), American Caucasians ( $87 \%$ correct), African-Americans ( $83 \%$ correct), and native Japanese ( $78 \%$ correct). Cultural variations in food preparation and smell and taste preference ${ }^{3}$ may account for the racial results observed in the present study and previous reports. In addition, environmental factors as well as cultural differences in familiarity with the test odors may have yielded race-dependent findings. Interestingly, the odorants most often incorrectly identified by the African-American population in the present study were fruit punch (34\% young African-Americans, $64 \%$ old African-Americans), cheddar cheese ( $41 \%$ young AfricanAmericans, $50 \%$ old AfricanAmericans), and coconut ( $37 \%$ young African-Americans, $32 \%$ old AfricanAmericans). Doty et al. ${ }^{5}$ observed that the odorant most likely to be incorrectly identified in all cultural groups was fruit punch.

Numerous systemic diseases and medications have been reported to alter the perception of smell. ${ }^{2,25-27}$ In the present study, significantly greater UPSIT scores were found in healthy elderly Caucasians compared with subjects with well-controlled hypertension; however, these differences were not evident in the African-American population. Interestingly, the three anosmic subjects in the study were older subjects treated for hypertension (two African-Americans, one Caucasian), whereas none of the healthy elderly was anosmic. However, the small sample size and the use of several different anti-hypertensive medications preclude the establishment of any relationships between hypertension and olfactory dysfunction. It is interesting, nevertheless, that previous studies ${ }^{2}$ have reported that hypertensive individuals have increased complaints of absent or diminished taste, especially for salt. Schiffman et al. ${ }^{2}$ demonstrated that the elderly have difficulty discerning differences in salt concentrations, and reported an 11.6-fold greater salt detection threshold in older compared with younger persons.

Caucasians had more complaints of smell problems than AfricanAmericans. There is no readily-available explanation why AfricanAmericans had no complaints of smell problems. It is suggested that a Likert scale be utilized in future studies to assess chemosensory complaints. ${ }^{32}$ The sensitivity for the changesmell question was low for both racial groups (African-

Americans 0\%, Caucasians 25\%), whereas the specificity was high (African-Americans $100 \%$, Caucasians $90 \%$ ). The results for the 
question changetaste were similar: low sensitivities (African-American $0 \%$, Caucasians $25 \%$ ) and high specificities (African-Americans 96\%, Caucasians $94 \%$ ). These findings indicate that the complaint of a smell problem does not necessarily indicate smell dysfunction. The high specificity establishes that normosmic individuals do not complain of chemosensory disturbances. These observations are consistent with those of previous studies. 1,12,28 Goodspeed et al. ${ }^{28}$ observed that patients who sought medical care for chemosensory disorders were unable to describe their chemosensory problem accurately. In general, many individuals are unable to distinguish between taste and smell.1,12,28 Individuals speak often of "tasting food", yet olfaction may contribute more than taste to the eating experience. ${ }^{24}$ Chemosensory disorders are caused by many factors, and may not necessarily reflect an olfactory or gustatory deficit. Therefore, it is imperative that these individuals receive thorough medical attention.

It is difficult to make generalizations about smell identification based upon this small study population. Because race is a multidimensional construct, ${ }^{29}$ future studies are clearly necessary to determine if race, culture, and ethnicity are significant attributes which influence chemosensory function. In addition, longitudinal studies are necessary to observe olfactory function in healthy people and individuals with systemic disease, to establish the influence of aging and disease on chemosensory performance.

We greatly appreciate the assistance of Dr. William Ebbs (NIDR, NIH) for data collection, Mia McCuiston (Spelman University) for data entry and analysis, and Drs. Bruce Baum (NIDR, NIH) and Phyllis Hayes-Reams (University of California, Los Angeles) for research guidance.

Dr. Jones is Dental Director, Odessa Brown Children's Clinic, 2101 East Yesler Way CN-06, Seattle, WA 98122 . Dr. Brown is a general practice resident at King's County Hospital, Brooklyn, NY. Dr. Ship is Associate Professor and Director of Hospital Dentistry,
Department of Oral Medicine/Pathology/ Surgery, University of Michigan School of Dentistry, Ann Arbor, MI 48109-1078. Please address correspondence/ requests for reprints to Dr. Jones.

1. Deems DA, Doty RL, Settle RG, et al. Smell and taste disorders, a study of 750 patients from the University of Pennsylvania Smell and Taste Center. Arch Otolaryngol Head Neck Surg 117:519-28, 1991.

2. Schiffman SS. Taste and smell in disease N Engl J Med 308(21):1275-1337, 1983.

3. Wysocki CJ, Pierce JD Jr, Gilbert AN. Geographic, cross-cultural, and individual variation in human olfaction. In: Getchell TV, et al. eds. Smell and taste in health and disease. New York: Raven Press, 287-313, 1991

4. Doty RL, Shaman P, Applebaum SL, Giberson R, Sikorski L, Rosenberg L. Smell identification ability: changes with age. Science 226(4681):1441-3, 1984.

5. Doty RL, Applebaum S, Hiroyuki Z, Settle RG. Sex differences in odor identification ability: a cross cultural analysis. Neuropsychologia 23:667-72, 1985.

6. Baum BJ. Characteristics of participants in the oral physiology component of the Baltimore longitudinal study of aging. Community Dent Oral Epidemiol 9:12834, 1981.

7. Shock NW, Greulich RC, Andres R, Arenberg D, Costa PT, Lakatta EG, et al. Normal human aging: the Baltimore longitudinal study of aging. NIH Publication No. 84-2450. Washington, DC: US Government Printing Office, 1984.

8. Ebbs W, Ship JA, Chohayeb A, Boyd J, Baum BJ. Oral health status in young and old, healthy urban blacks (abstract). I Dent Res 71:242, 1992.

9. Jones R, Ship JA. Major salivary gland flow rates in young and old, generally healthy, blacks and whites. J Natl Med Assoc 87:131-5, 1995.

10. Weber MA, Neutel JM, Cheung DG Hypertension in the aged: a pathophysiologic basis for treatment. Am J Cardiol 63:25H-32H, 1989.

11. Doty RL, Shaman P, Dann M. Development of the University of Pennsylvania Smell Identification Test: a standardized microencapsulated test of olfactory function. Physiol Behav 32:489502,1984

12. Ship JA, Weiffenbach JM. Age, gender, medical treatment, and medication effects on smell identification. I Gerontol Med Sci 48(1):M26-32, 1993.

13. Doty RL. The smell identification test administration manual. Haddonfield, $\mathrm{NJ}$ : Sensonics, Inc, 1983.

14. Schiffman $\mathrm{S}$. Food recognition by the elderly. J Gerontol 32(5):586-92, 1977.

15. Schiffman SS. Perception of taste and smell in elderly persons. Crit Rev Food Sci Nutr 33(1):17-26, 1993.
16. Getchell TV, Heck GL, DeSimone JA, et al. The location of olfactory receptor sites. Biophys J 29:397-411, 1980.

17. Nakashima T, Kimmelman CP, Snow JB. Structure of human fetal and adult olfactory neuroepithelium. Arch Otolaryngol 110:641-6, 1984

18. Hornung DE, Mozell MM. Smell: human physiology. New York: Macmillan, 19-38, 1986.

19. Morrison EE, Costanzo RM. Morphology of the human olfactory epithelium. J Comp Neurol 297:1-13, 1990.

20. Mott AE, Leopold DA. Disorders in taste and smell. Med Clin North Am 75:132152,1991

21. Ship JA, Ship II. Trends in oral health in the aging population. Dent Clin North Am 33:33-42, 1989

22. Catalanotto FA, Sweeney EA. Oral conditions affecting chemosensory function. In: Getchell TV, Doty RL, Bartoshuk LM, Snow $\mathrm{JB} \mathrm{Jr}$, eds. Smell and taste in health and disease. New York: Raven Press, 643-51, 1991.

23. Doty RL. Gender and endocrine-related influence upon olfactory sensitivity. In Meiselman HL, Rivlin RS, eds. Clinical measurement of taste and smell. New York: Macmillan, 377-413, 1985.

24. Bartoshuk LM, Weiffenbach JM. Chemical senses and aging. In: Schneider EL, Rowe JW, eds. Handbook of the biology of aging. San Diego: Academic Press, 1429$43,1990$.

25. Doty RL. Influence of age and age-related diseases on olfactory function. Ann NY Acad Sci 561:76-86, 1989

26. Doty RL. Olfactory dysfunction in neurodegenerative disorders. In: Getchell TV, Doty RL, Bartoshuk LM, Snow JB Jr, eds. Smell and taste in health and disease. New York: Raven Press, 735-52, 1991.

27. Doty RL, Bartoshuk LM, Snow JB Jr. Causes of olfactory and gustatory disorders. In: Getchell TV, Doty RL, Bartoshuk LM, Snow JB Jr, eds. Smell \& taste in health \& disease. New York: Raven Press, 449-67, 1991.

28. Goodspeed RB, Catalanotto FA, Gent JF, et al. Clinical characteristics of patients with taste and smell disorders. In: Meiselman HL, Rivilin RS, eds. Clinical measurements of taste and smell. New York: Macmillan Publishing Co. Inc., 45166, 1986.

29. LaVeist TA. Beyond dummy variables and sample selection: what health services researchers ought to know about race as a variable. Health Serv Res 29:1$15,1994$.

30. Weiffenbach JM, Bartoshuk LM. Taste and smell. Clin Ger Med 8(3):543-55, 1992.

31. Stevens JC, Plantinga A, Cain WS. Reduction of odor and nasal pungency associated with aging. Neurobiol Aging 3:125-32, 1982.

32. Bucher L. Evaluating the affective domain: consider a Likert scale. J Nurs Staff Dev 7(5):234-8, 1991. 